\title{
Spatial-temporal changes in vegetation coverage in the global coastal zone based on GIMMS NDVI3g data
}

\section{Wan Hou \& Xiyong Hou}

To cite this article: Wan Hou \& Xiyong Hou (2020) Spatial-temporal changes in vegetation coverage in the global coastal zone based on GIMMS NDVI3g data, International Journal of Remote Sensing, 41:3, 1118-1138, DOI: 10.1080/01431161.2019.1657603

To link to this article: https://doi.org/10.1080/01431161.2019.1657603

曲 Published online: 27 Aug 2019.

Submit your article to this journal $\widetilde{ }$

III Article views: 134

Q View related articles $\widetilde{ }$

View Crossmark data $\nearrow$

Citing articles: 1 View citing articles 지 


\title{
Spatial-temporal changes in vegetation coverage in the global coastal zone based on GIMMS NDVI3g data
}

\author{
Wan Hou ${ }^{\mathrm{a}, \mathrm{b}, \mathrm{c}}$ and Xiyong Hou ${ }^{\mathrm{a}, \mathrm{c}}$ \\ aYantai Institute of Coastal Zone Research, Chinese Academy of Sciences, Yantai, China; ${ }^{b}$ College of \\ Resources and Environment, University of Chinese Academy of Sciences, Beijing, China; 'Key Laboratory of \\ Coastal Environmental Processes and Ecological Remediation, Chinese Academy of Sciences, Yantai, China
}

\begin{abstract}
In this paper, we used the Global Inventory Modelling and Mapping Studies (GIMMS) third-generation Normalized Difference Vegetation Index (NDVI) (GIMMS NDVI3g) dataset. Based on GIMMS NDVI3g data over the global coastal zone from 1982 to 2014, the spatial-temporal characteristics of vegetation coverage were analysed by plotting the spatial pattern and monthly calendar of NDVl; furthermore, historical trends and future evolutions of vegetation coverage change at the pixel scale were studied by performing the Mann-Kendall trend test and calculating the trend slope $(\beta)$ and Hurst index $(H)$ of NDVI. The main findings are as follows: 1) Vegetation density exhibits dramatic differences in the global coastal zone. Specifically, desert belts mostly have perennial non-vegetation or low vegetation coverage, and tundra belts principally have moderate or high vegetation coverage; additionally, forest belts mainly have dense vegetation coverage. 2) In the global coastal zone, intra-annual variations in vegetation coverage show a ' $\cap$ '-shaped curve with an obvious peak from June to September (maximum in July or August), while interannual variations show a fluctuating but generally slowly increasing trend over the entire study period; accordingly, variations in different subregions show significant differences. 3) At monthly, seasonal and annual scales, the overall vegetation coverage increases in the global coastal zone, while there are relatively few areas with decreasing vegetation coverage; furthermore, change trends of vegetation coverage in most areas will demonstrate relatively strong positive persistence in the future. 4) The increasing trend in high-latitude coastal tundra is extremely significant in the growing season because vegetation in the tundra belts is highly sensitive to climate change. 5) Areas with a decreasing trend of vegetation coverage exhibit spatial patterns of aggregation in the 'circum urban agglomeration' and 'nearby desert belt' regions, that is, the decreasing trend of vegetation coverage is relatively high in coastal urban agglomeration areas and desert belt peripheries. This paper is expected to provide knowledge to support vegetation conservation, ecosystem management, integrated coastal zone management and climate change adaptation in coastal areas.
\end{abstract}

\section{ARTICLE HISTORY}

Received 8 April 2018

Accepted 10 June 2019

CONTACT Xiyong Hou xyhou@yic.ac.cn @ Yantai Institute of Coastal Zone Research, Chinese Academy of Sciences, Yantai 264003, China 


\section{Introduction}

Vegetation makes up a critical component of terrestrial ecosystems, serving as a bond linking eco-environmental elements such as air, water and soil, and plays an irreplaceable role in material cycling, energy flows and carbon balance regulation the global scale (Pereira et al. 2013; Shafapour Tehrany, Kumar, and Drielsma 2017). Vegetation dynamics, representing dynamic and continuous processes, reflect synthetic action with regard to climate change and human activity (Kim et al. 2017); therefore, it is important to monitor vegetation changes. The Normalized Difference Vegetation Index (NDVI) is an effective indicator of vegetation density and growth status, accurately characterizing coverage information of terrestrial vegetation (Vrieling et al. 2014; Vicente-Serrano et al. 2016; Fan and Liu 2016). Time series of NDVI data derived from the Global Inventory Modelling and Mapping Studies (GIMMS) are widely used. Given that the GIMMS NDVI dataset has many advantages, such as a long time series, high spatial coverage, and detailed coverage information, this dataset contains among the most effective data to explore vegetation changes at large spatial scales and over long periods of time (Du et al. 2016; Pang, Wang, and Yang 2017). Many studies on terrestrial vegetation coverage based on the GIMMS NDVI data have been reported at different spatial and temporal scales, with a primary focus on the change rule, development trend, driving mechanism and influence effect on climate change. For example, Lanfredi, Simoniello, and Macchiato (2004) revealed the persistent characteristics of vegetation in Italy for the period from 1985-1999 and quantitatively predicted the trend duration of vegetation change. Miao et al. (2015) analysed change rules of vegetation coverage on the Mongolian Plateau for the period 1982-2011. Yang et al. (2016) discussed changes in vegetation coverage and the driving factors of these changes in the Hexi region of Northwest China over the last three decades. Lamchin et al. (2017) studied trends and correlations between climate change and vegetation greenness in Asia from 1982-2014. To date, most studies have investigated terrestrial areas, such as forest, arid, and semi-arid regions (Du et al. 2015; De Keersmaecker et al. 2017; Xu, Wang, and Yang 2017), while there are relatively few studies on coastal areas (Ju and Masek 2016).

Global coastal zone, where cities, populations and industries are clustered, is located between marine ecosystems and terrestrial ecosystems, serving as an important 'window' area in which to study earth system science (Masria et al. 2014) and is composed of fragile eco-environmental areas that are strongly affected by human activity and climate change (Halkos and Matsiori 2018). Therefore, it is important to understand the long-term spatialtemporal dynamics of vegetation coverage in the global coastal zone, which are important indicators of coastal environmental change, to reveal coastal ecosystem succession and to explore the effects of climate change on coastal areas. In recent years, the research advances on vegetation coverage in coastal areas are sparse. Specifically, studies on vegetation coverage in coastal areas are not common, and most of these studies have investigated microscale or mesoscale regions (de la Barrera and Henríquez 2017; Rêgo, Soares-Gomes, and Da Silva 2018); furthermore, very few studies have focused on vegetation coverage changes in the global coastal zone. Comprehensive and well-researched studies on vegetation coverage in coastal areas have been reported at the regional scale. For example, the characteristics of multi-temporal scale variation in vegetation coverage in the circum Bohai Bay region from 1999 to 2009 were investigated using the Mann-Kendall trend test and Hurst index (Hou et al. 2012), changes in vegetation photosynthetic activity 
across the Asia-Pacific region from 1982-2011 were monitored using least-square linear regression, breakpoint and turning point (Chen et al. 2014), seasonal and inter-annual changes in the vegetation activity of tropical forests in Southeast Asia were examined using three independent, satellite-derived, NDVI products (Zhang et al. 2016), and the character and trends of vegetation coverage change along coastal areas of the Maritime Silk Road from 2000-2016 were studied using change vector analysis, linear regression and Hurst index (Wang, Yang, and Zhang 2018).

A fundamental goal of coastal zone management is to minutely analyse and deeply reveal spatial-temporal changes in vegetation coverage in the global coastal zone. Therefore, based on the GIMMS NDVI3g dataset over the global coastal zone from 1982 to 2014, we perform the Mann-Kendall trend test and calculate the trend slope $(\beta)$ and Hurst index $(H)$ of NDVI time series to study the historical trends and future evolutions of vegetation coverage change at the pixel scale. And, we plot the spatial pattern, monthly calendar and seasonal succession map using spatial analysis techniques to analyse the spatial-temporal characteristics of vegetation coverage at the multi-temporal scale. Overall, this paper aims to provide knowledge to support vegetation conservation, ecosystem management, integrated coastal zone management and climate change adaptation in coastal areas.

\section{Study area and materials}

\subsection{Study area}

In this paper, the global coastal zone is defined as the land within $100 \mathrm{~km}$ of the coastline but does not include large inland lakes and coastal areas of Antarctica (Shi and Singh 2003). This area covers most of the global coastal land, where the vegetation characteristics are as follows: 1) the vegetation distribution shows significant zonality, affected by latitude, landsea patterns, ocean currents, climate, landforms and landscapes at regional and global scales (Feng, Zou, and Luo 2017); 2) the vegetation types are mainly tropical rainforest, tropical grassland, subtropical evergreen broad-leaved forest, subtropical evergreen hardwood forest, temperate mixed forest, temperate deciduous broad-leaved forest, temperate grassland, subfrigid coniferous forest, tundra, ice sheet, desert and alpine flora; 3) the vegetation coverage has significant spatial-temporal changes caused by climate change, population agglomeration and socio-economic development (Dobbs, Nitschke, and Kendal 2017; Zhao, Dai, and Dong 2018). To further facilitate our research, we divided the study area (Glo-Global coastal zone) into eight subregions (Figure 1): NAm-North American coastal zone, SAm-South American coastal zone, Afr-African coastal zone, Oce-Oceanian coastal zone, Eur-European coastal zone, NAs-North Asian coastal zone, ESE-East Asian and Southeast Asian coastal zones, and SSW-South Asian and Southwest Asia coastal zones.

\subsection{Materials}

The GIMMS NDVI3g dataset was obtained from the Global Inventory Modelling and Mapping Studies (GIMMS) using the Advanced Very High-Resolution Radiometers (AVHRR) onboard the National Oceanic and Atmospheric Administration (NOAA) satellites (Latifovic, Pouliot, and Dillabaugh 2012). During pre-processing, which involved radiation 


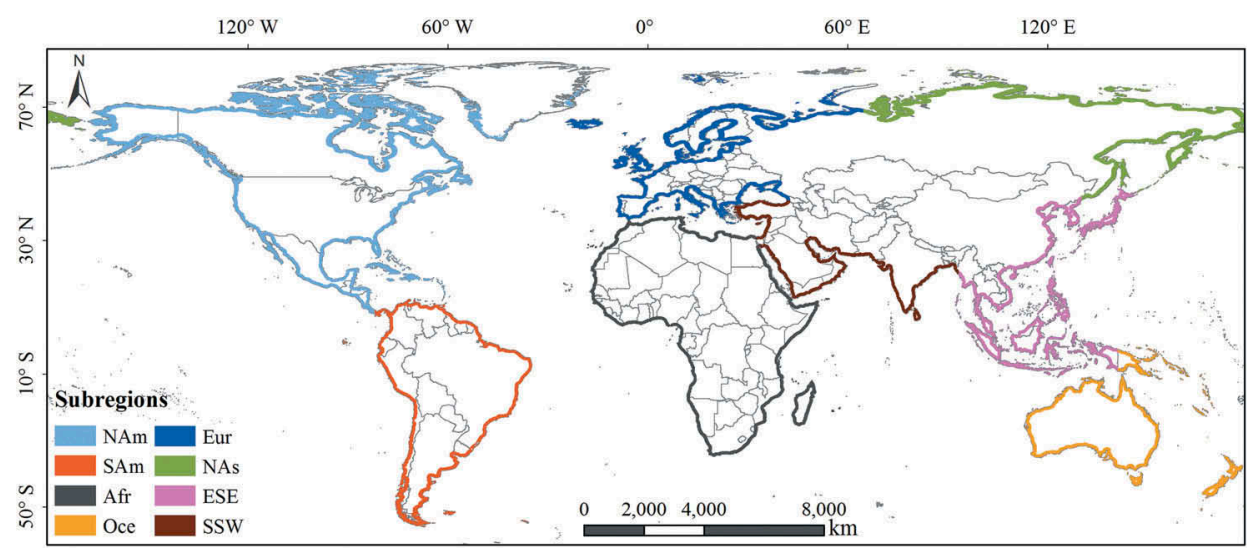

Figure 1. The location, extent and subregions of the study area (background: national boundaries).

correction, geometric correction, cloud removal and bad-line removal, a third-generation half-month NDVI dataset at a spatial resolution of $0.083^{\circ} \times 0.083^{\circ}$ was generated (Pinzon and Tucker 2014). This NDVI3g dataset currently (https://ecocast.arc.nasa.gov/data/pub/ gimms/) has the longest available time series, which extends from 1981 to the present. We extracted the GIMMS NDVI3g dataset, which includes data for the land within $100 \mathrm{~km}$ of the coastline from 1982 to 2014, and transformed the projected coordinate system into a Cylindrical_Equal_Area projection.

\section{Methods}

\subsection{Time-scale transformation}

The maximum value composite (MVC) method is widely used to eliminate noise mainly caused by clouds, air, solar azimuth angles, and other factors (Holben 1986). With this method, we obtained NDVI3g data at monthly and annual scales. The formula used is as follows:

$$
\mathrm{NDVI}_{i}=\operatorname{Max}\left(\mathrm{NDVI}_{i j}\right)
$$

where $\mathrm{NDVI}_{i}$ is the NDVI data for month $i$ or year $i$ and $\mathrm{NDVI}_{i j}$ is the NDVI data for halfmonth $j$ or month $j$ in month $i$ or year $i$.

\subsection{Mann-Kendall trend test}

The Mann-Kendall (M-K) trend test is an effective method to reveal the change trend and significance of time series that is widely used in trend analysis (Yue, Pilon, and Cavadias 2002). For the time series $\left\{x_{1}, x_{2}, \ldots, x_{n}\right\}, n$ is the length of series, and the formula is as follows (Hamed 2009):

$$
S=\sum_{j=1}^{n-1} \sum_{k=j+1}^{n} \operatorname{sgn}\left(x_{k}-x_{j}\right)
$$




$$
\operatorname{sgn}\left(x_{k}-x_{j}\right)=\left\{\begin{array}{cc}
1 & x_{k}-x_{j}>0 \\
0 & x_{k}-x_{j}=0 \\
-1 & x_{k}-x_{j}<0
\end{array}\right.
$$

where $S$ is the test statistic and $x_{k}$ and $x_{j}$ are the corresponding NDVI data for year $k$ and year $j$, respectively, where $k$ is greater than $j$. The test statistic $Z$ is given by

$$
\begin{gathered}
Z=\left\{\begin{array}{cl}
\frac{s-1}{\sqrt{\operatorname{Var}(s)}} & S>0 \\
0 & S=0 \\
\frac{s+1}{\sqrt{\operatorname{Var}(s)}} & S<0
\end{array}\right. \\
\operatorname{Var}(s)=\frac{n(n-1)(2 n+5)}{18}
\end{gathered}
$$

At the significance level of $95 \%$, if $|Z| \geq 1.96$, the time series has a significant increasing or decreasing trend over time. Then, slope $\beta$, which indicates the trend of the time series, is calculated by

$$
\beta=\operatorname{Median}\left(\frac{x_{k}-x_{j}}{k-j}\right), \forall j<k
$$

If $\beta>0$, the time series has an increasing trend; if $\beta<0$, the series has a decreasing trend; notably, if $\beta=0$, the series is discrete and random.

According to the combined analysis of $\beta$ and $|Z|$ at the pixel scale, different quantitative combinations indicate different ecological meanings (Table 1).

\subsection{Hurst index}

The Hurst $(H)$ index can describe the self-similarity and long-range dependence of time series quantitatively (Peng et al. 2012). If $H<0.5$, the time series is an anti-persistent series, that is, the series of change trends in the past will most likely reverse in the future; if $H=0.5$, the time series is an independent discrete series; if $0.5<H<1$, the time series is a persistent series, that is, the series of change trends in the past will most likely be maintained in the future. The R/S analysis method effectively calculates the Hurst index, and the principles are described as follows (Sánchez Granero, Trinidad Segovia, and García Pérez 2008).

For a time series $\{\xi(t)\}, t=1,2, \ldots, n$; define another series $\tau=1,2, \ldots, n$; for a certain $\tau$, define the mean sequence:

Table 1. Indicative meanings of combinations of $\beta$ and $|Z|$ values.

\begin{tabular}{lcl}
\hline$\beta$ & $|Z|$ & Trend of vegetation coverage change \\
\hline- & - & Non-vegetation coverage \\
$>0$ & $\geq 1.96$ & Significantly increasing \\
$<0$ & $\geq 1.96$ & Significantly decreasing \\
$<0$ & $<1.96$ & Insignificantly decreasing \\
$>0$ & $<1.96$ & Insignificantly increasing \\
0 & - & Discrete sequence \\
\hline
\end{tabular}

Non-vegetation coverage: the NDVI time series average is less than 0.1. Discrete sequence: the change in the time series is discrete and random. 


$$
\langle\xi\rangle_{\tau}=\frac{1}{\tau} \sum_{t=1}^{\tau} \xi(t)
$$

For time $\tau$, calculate the cumulative deviation:

$$
X(t, \tau)=\sum_{u=1}^{t}\left(\xi(u)-\langle\xi\rangle_{\tau}\right) 1 \leq t \leq \tau
$$

Next, define the range sequence $R(\tau)$ and the standard deviation sequence $S(\tau)$ :

$$
\begin{gathered}
R(\tau)=\max \underset{1 \leq t \leq \tau}{X}(t, \tau)-\min \underset{1 \leq t \leq \tau}{X}(t, \tau) \\
S(\tau)=\sqrt{\frac{1}{\tau} \sum_{t=1}^{\tau}\left(\xi(t)-\langle\xi\rangle_{\tau}\right)^{2}}
\end{gathered}
$$

Then, obtain an exponential law:

$$
\frac{R(\tau)}{S(\tau)}=(c \tau)^{H}
$$

where $H$ is the Hurst index, $c$ is a constant, and $\tau$ is the length of the time series.

\subsection{Indicative joint meanings of $\beta$ and $H$ values}

With the combined analysis of Mann-Kendall slope $(\beta)$ and Hurst index $(H)$, historical trends and future evolutions of time series can be comprehensively revealed (Liu et al. 2016; Tian et al. 2017). Specifically, we can modify $H$ by subtracting 0.5 from the value of $H$, making $H$ range from -0.5 to 0.5 . By establishing a cartesian coordinate system in which $\beta$ and $H-0.5$ are the $x$-coordinate and $y$-coordinate values, respectively, $\beta-(H-0.5)$ data at the pixel scale can be plotted as points within this coordinate system; notably, points in different quadrants have different ecological meanings (Table 2).

Table 2. Indicative meanings of combinations of $\beta$ and $H$ minus 0.5 .

\begin{tabular}{lccc}
\hline$x$-coordinate: $\beta$ & $y$-coordinate: $H-0.5$ & Quadrant & Evolution of vegetation coverage change \\
\hline$>0$ & - & - & $\begin{array}{l}\text { Non-vegetation coverage } \\
\text { Increasing trend in the past and go on increasing in the } \\
\text { future } \\
\text { Decreasing trend in the past and go on decreasing in } \\
\text { the future }\end{array}$ \\
$<0$ & $>0$ & Second quadrant & $\begin{array}{l}\text { Decreasing trend in the past while have opposite trend } \\
\text { in the future } \\
\text { Increasing trend in the past while have opposite trend } \\
\text { in the future } \\
\text { Discrete sequence }\end{array}$ \\
\hline
\end{tabular}

Non-vegetation coverage: the NDVI time series average is less than 0.1. Discrete sequence: the change in the time series is discrete and random. 


\section{Results}

\subsection{Spatial patterns of vegetation coverage}

The average annual NDVI from 1982 to 2014 was calculated to reflect the overall longterm spatial patterns of vegetation coverage (Figure 2); values and area proportions of the average annual NDVI during the entire study period were calculated for different geographic regions (Table 3). Specifically, the study area was divided into perennial nonvegetation coverage (NDVI value from 0 to 0.10 ), low vegetation coverage (NDVI value from 0.10 to 0.35 ), moderate vegetation coverage (NDVI value from 0.35 to 0.60 ), high vegetation coverage (NDVI value from 0.60 to 0.85 ) and dense vegetation coverage (NDVI value from 0.85 to 1 ) areas using the vegetation coverage partition method.

Areas of perennial non-vegetation coverage and low vegetation coverage account for $20.12 \%$ of the whole area and mainly include the Canadian Arctic Archipelago, Mexican Baja California Peninsula, junction coasts of Chile and Peru, Argentinean south coast, Namibian coast, Saharan west coast, coasts from Libya to Somalia, Australian west and south coasts, and coasts from the Arabian Peninsula to Pakistan; therefore, in addition to the tundra and ice sheet belts with an ephemeral growing season in the Canadian Arctic Archipelago, the regions with no vegetation coverage are mostly desert belts. Areas of moderate vegetation coverage and high vegetation coverage comprise $51.26 \%$ of the entire area and are widely spread along the low-middle latitude coasts; however, the tundra belt on the northern high-latitude coasts of North America and Eurasia has a relatively high annual NDVI value. Twenty-eight per cent of all global coasts, mainly

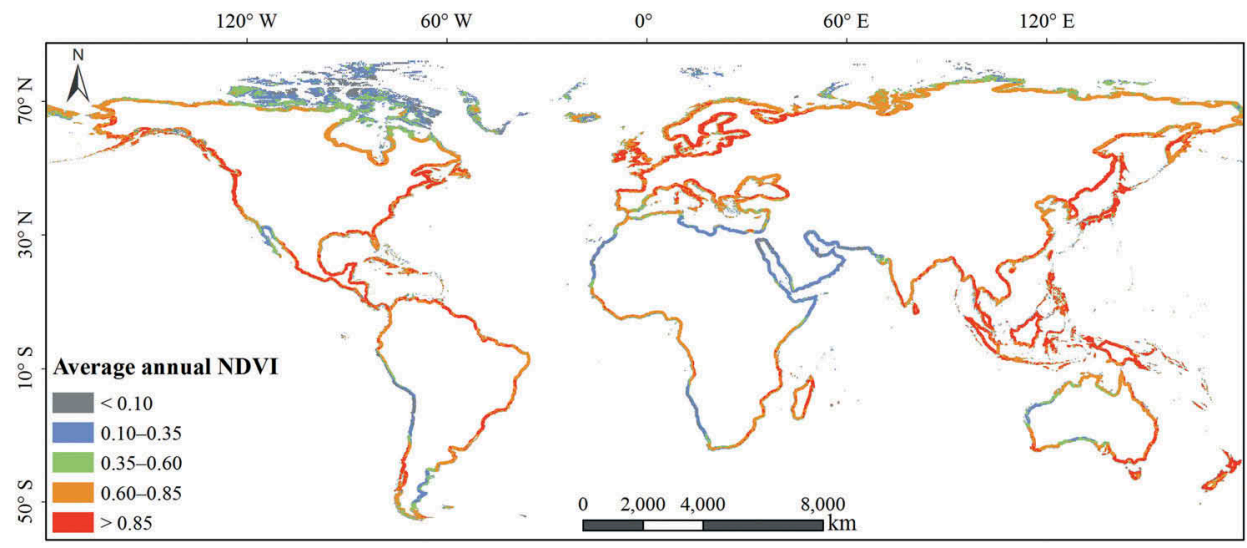

Figure 2. Spatial patterns of NDVI in the global coastal zone.

Table 3. Values and area proportions of the average annual NDVI from 1982 to 2014.

\begin{tabular}{|c|c|c|c|c|c|c|c|c|c|c|}
\hline \multirow[b]{2}{*}{ Vegetation coverage type } & \multirow{2}{*}{$\begin{array}{c}\text { NDVI } \\
\text { domain }\end{array}$} & \multicolumn{9}{|c|}{ Area proportion for geographic region (\%) } \\
\hline & & Glo & NAm & SAm & Afr & Oce & Eur & NAs & ESE & SSW \\
\hline Perennial non-vegetation coverage & $<0.10$ & 4.61 & 7.17 & 6.15 & 6.58 & 2.43 & 1.11 & 1.02 & 1.31 & 10.79 \\
\hline Low vegetation coverage & $0.10-0.35$ & 15.51 & 16.45 & 13.57 & 31.68 & 11.12 & 5.31 & 4.45 & 7.69 & 39.66 \\
\hline Moderate vegetation coverage & $0.35-0.60$ & 15.29 & 21.76 & 13.80 & 14.43 & 18.20 & 11.68 & 16.68 & 9.31 & 12.11 \\
\hline High vegetation coverage & $0.60-0.85$ & 35.97 & 29.02 & 40.63 & 37.15 & 37.59 & 42.88 & 58.72 & 30.03 & 25.27 \\
\hline Dense vegetation coverage & $>0.85$ & 28.62 & 25.60 & 25.85 & 10.16 & 30.66 & 39.02 & 19.13 & 51.66 & 12.17 \\
\hline
\end{tabular}


across the Canadian west coast, American east coast, Mexican coast, Chilean south coast, Brazilian north and south coasts, Australian east coast, Zelanian coast, European coast, and East Asian and Southeast Asian coasts, have dense vegetation coverage; furthermore, the vegetation in these regions mostly belongs to the temperate mixed forest, temperate deciduous broad-leaved forest, subtropical evergreen hardwood forest, subtropical evergreen broad-leaved forest, tropical grassland and tropical rainforest types.

\subsection{Temporal changes in vegetation coverage}

The regional average monthly NDVI values in the whole study area and in each of the eight subregions were summed, and the monthly calendars of vegetation coverage were plotted, as shown in Figure 3, which displays the intra-annual NDVI variations (horizontal axis) of every year and the inter-annual NDVI variations (vertical axis) of every month; the regional average annual NDVI values and the multi-year average of regional average monthly NDVI values in different geographic regions were summed, and the variation curves at annual and monthly scales were plotted, as shown in Figure 4.

As shown in Figures 3 and 4(b), the intra-annual variations in vegetation coverage are as follows: Glo, NAm, Eur, NAs and ESE have similar characteristics, that is, the regions demonstrate significant alternating features in the growing season and non-growing season, showing a ' $\cap$ '-shaped curve with an obvious peak from June to September (maximum in July or August). However, there are also significant differences among
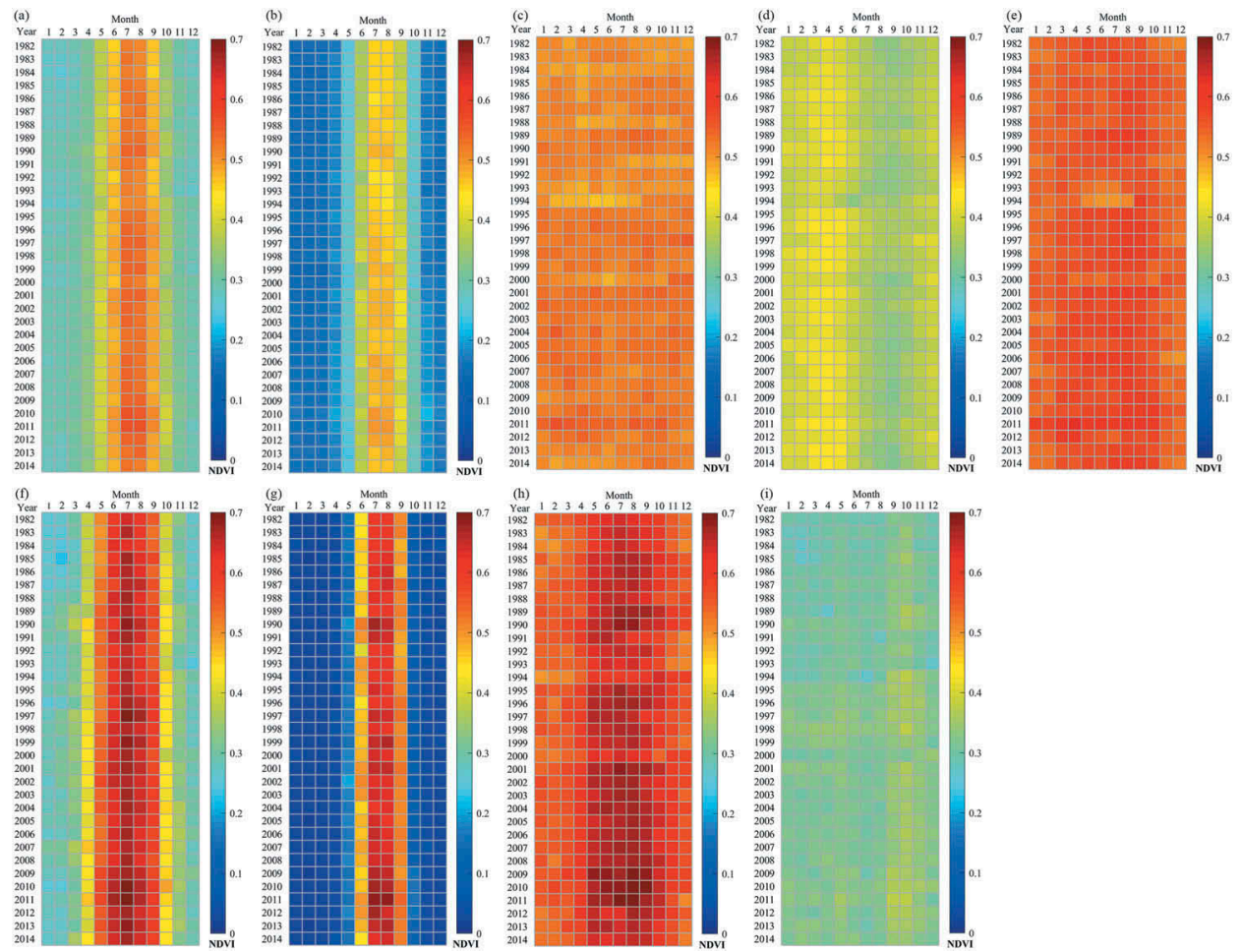

Figure 3. Monthly calendars of NDVI (a-Glo; b-NAm; c-SAm; d-Afr; e-Oce; f-Eur; g-NAs; h-ESE; i-SSW). 

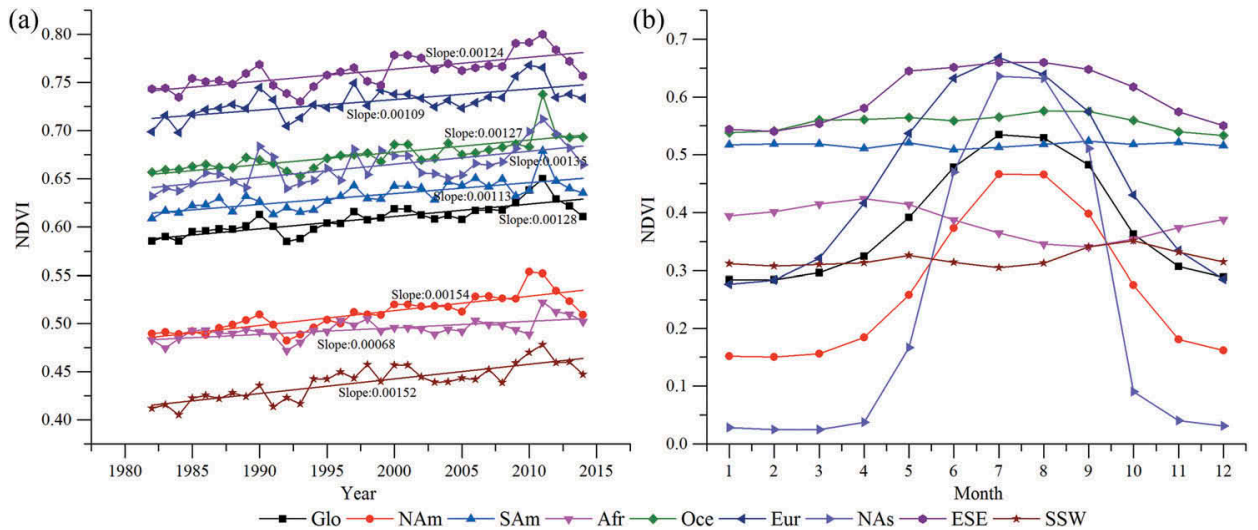

Figure 4. Variations in NDVI at annual (a) and monthly (b) scales.

these regions as follows: NAm and NAs have a significant low-order (low value) ' $\cap$ 'shaped curve, that is, the lengthy non-growing season has an extremely low value and the transitory growing season has a middle-high value; Eur and ESE have a significant high-order (high value) ' $\cap$ '-shaped curve, that is, the non-growing season has a middlehigh value and the growing season has an extremely high value; Glo is a global mean state with high numerical values. Afr has a relatively obvious ' $U$ '-shaped curve with a valley from July to October, which differs from the shape of other regions; the reason for this difference is that the major vegetation type in Afr is tropical grassland, and Afr straddles the Equator, where the growing and non-growing seasons are opposite those in the Northern Hemisphere. SAm, Oce and SSW, which have broadly similar characteristics, belong to an intra-annual 'stable'-shaped curve, that is, there are no obvious seasonal differences in these regions; these regions are located in low-middle latitudes near the Equator, and vegetation types in these regions are largely tropical rainforest and tropical grassland. Furthermore, SSW has a low-order (low value) 'stable'-shaped curve, while SAm and Oce have a high-order (high value) 'stable'-shaped curve.

As shown in Figures 3 and 4(a), the inter-annual variations in vegetation coverage are as follows: for the period of 1982-2014, the NDVI in each month of the entire study area and the eight subregions all fluctuate but generally slowly increase; the annual NDVI values of Glo, NAm, SAm, Afr, Oce, Eur, NAs, ESE and SSW fluctuate in the ranges of $0.58-0.66,0.48-0.56,0.60-0.68,0.47-0.53,0.65-0.74,0.69-0.77,0.63-0.72,0.73-0.81$ and $0.40-0.48$, respectively, and the values of these regions are all slowly increasing, with rising slopes that show the order of NAm $>$ SSW $>$ NAs $>$ Glo $>$ Oce $>$ ESE $>$ SAm $>$ Eur $>$ Afr. The fluctuation traits of NDVI in different geographic regions have an extremely high consistency, that is, the maximum and minimum values of the annual NDVI show relatively strong regularity; generally speaking, the maximum values of NDVI in Glo, SAm, Afr, Oce, NAs, ESE and SSW occur in 2011, while those in NAm and Eur occur in 2010, and the minimum values of NDVI in Glo, NAm and Afr occur in 1991, those in SAm and NAs occur in 1982, those in Oce and ESE occur in 1993, and those in Eur and SSW occur in 1984. 


\subsection{Changes in vegetation coverage at the pixel scale}

\subsubsection{Change trends in vegetation coverage from 1982 to 2014}

According to the indicative meanings of $\beta$ and $|Z|$ jointly at the pixel scale, the proportions of pixels with different trends of vegetation coverage change in the global coastal zone at annual and monthly scales are summarized in Figure 5, and the spatial patterns of $\beta$ and $|Z|$ jointly at the annual scale are plotted in Figure 6 .

At an annual scale, the vegetation coverage in the global coastal zone is increasing overall because $60.87 \%$ of the pixels reveal an increasing trend; furthermore, 'significantly increasing' pixels are most widespread, accounting for $33.48 \%$ of all pixels, and 'insignificantly increasing' pixels account for $27.39 \%$ of all pixels. Accordingly, there are relatively few pixels with decreasing trends, which make up $30.05 \%$ of all pixels, and 'insignificantly decreasing' and 'significantly decreasing' pixels make up $19.16 \%$ and $10.89 \%$ of all pixels, respectively. As shown in Figure 6 , areas with increasing vegetation coverage trends in the global coastal zone at an annual scale are mostly distributed in high-latitude tundra belts with an ephemeral growing season, middle-latitude temperate mixed forest and temperate deciduous broad-leaved forest belts, and low-latitude tropical grassland and tropical rainforest belts near the Equator. Accordingly, areas with decreasing trends, which are mainly dispersed within areas with increasing trends, show the 'locally concentrated' spatial patterns; these regions are mainly in coastal urban agglomeration areas and desert belt peripheries.

At a monthly scale, as shown in Figure 5, in addition to 'non-vegetation coverage' and 'discrete sequence' areas, the proportions of pixels with different trends in the global coastal

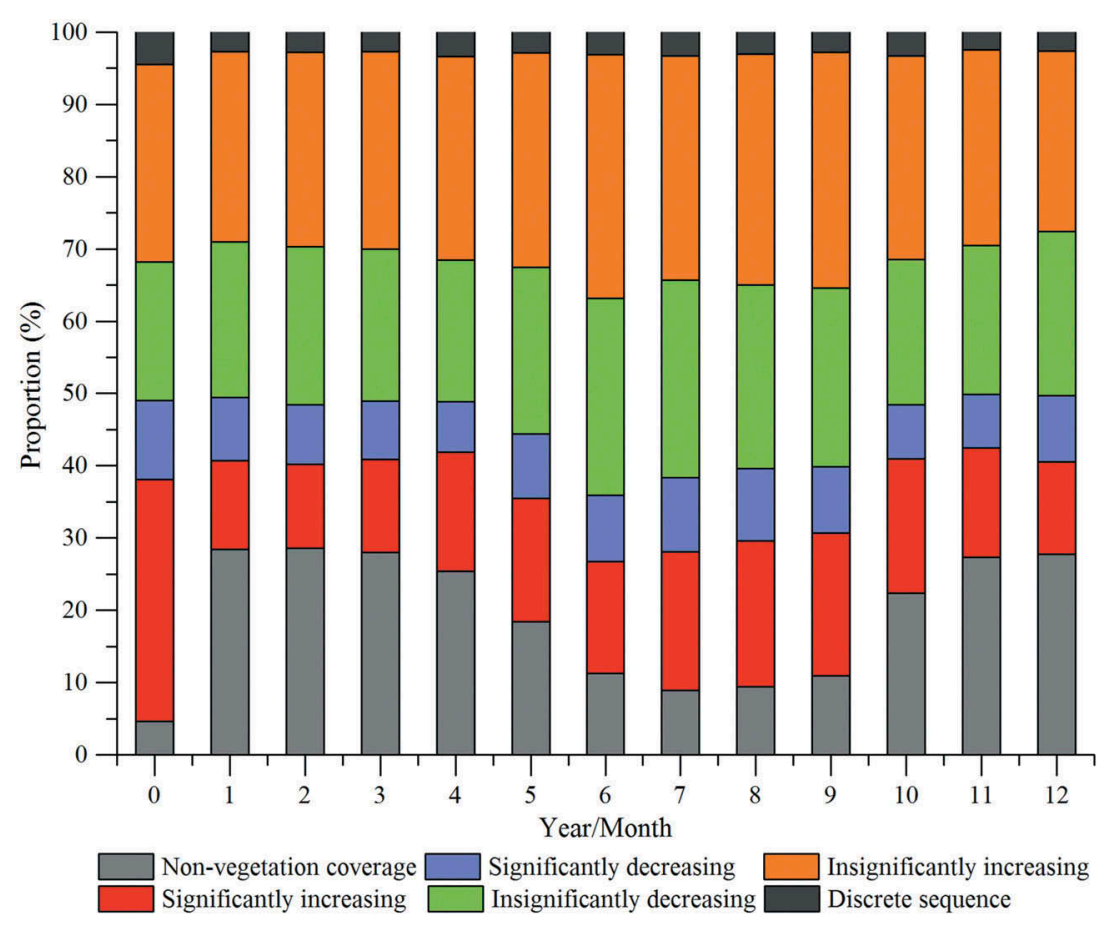

Figure 5. Trends of $\beta$ and $|Z|$ jointly at annual (0) and monthly (1-12) scales. 


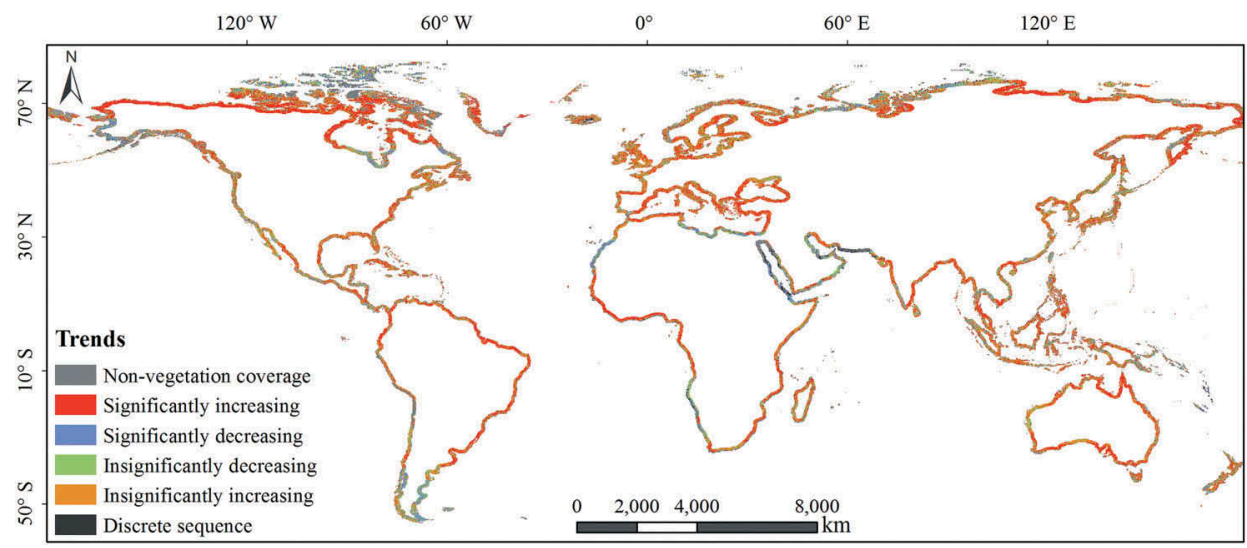

Figure 6. Spatial patterns of $\beta$ and $|Z|$ jointly at the annual scale.

zone maintain the order of 'insignificantly increasing' > 'insignificantly decreasing' > 'significantly increasing' > 'significantly decreasing' over 12 months. Additionally, the abovementioned four trends have similar intra-annual variations that show a peak from June to September, and these trends also have obvious differences as follows: 'insignificantly increasing' and 'significantly increasing' pixels show extremely low values from December to February, while 'insignificantly decreasing' and 'significantly decreasing' pixels show low values in April and October. Overall, the dominant vegetation coverage change characteristic in the global coastal zone at a monthly scale is 'increasing (insignificantly and significantly)', and the intra-annual variations show a ' $\cap$ '-shaped curve with a peak in September; additionally, 'decreasing (insignificantly and significantly)' change is the second most dominant in the global coastal zone, with intra-annual variations that show a 'reversed $\mathrm{M}^{\prime}$ shaped curve with two valleys in April and October; these shapes indicate that the overall increasing trend of vegetation coverage in the global coastal zone is the most notable in April, September and October because spring in the Northern Hemisphere occurs in April, while spring in the Southern Hemisphere occurs in September and October.

A comparison of the number of pixels with different trends at annual and monthly scales indicates that the annual NDVI data obtained from the MVC method mainly reveal vegetation coverage information in the high-growth season; in particular, vegetation coverage change shows an extremely significant increasing trend in the vegetation belts with an ephemeral growing season, where vegetation is highly sensitive to climate change, such as in the high-latitude tundra belts.

\subsubsection{Persistence of vegetation coverage change}

According to the indicative meanings of $\beta$ and $H-0.5$ jointly at the pixel scale, the proportions of pixels with different evolutions of vegetation coverage change were calculated in the whole study area and in the eight subregions over 12 months (Figure 7).

'Discrete sequence' pixel ratios have nearly no intra-annual variations in the whole study area and eight subregions. In particular, 'discrete sequence' proportions in Afr and Oce are relatively high and exceed 5\%; these pixels, where the vegetation type is largely tropical rainforest, are mainly spread near the Equator. As shown in Figure 7, different 

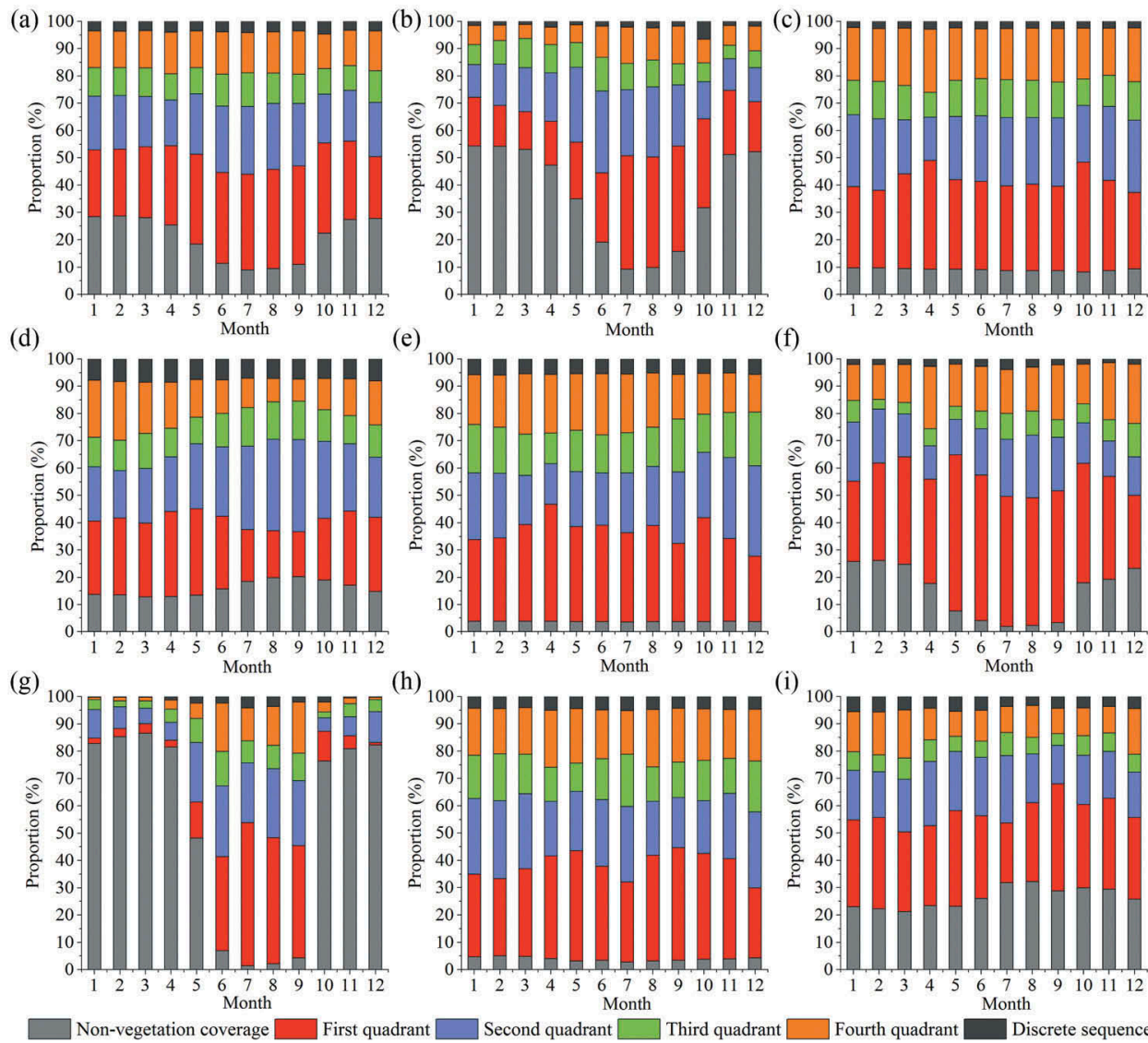

Figure 7. Quadrantal distributions of $\beta$ and $H-0.5$ jointly at the pixel scale (a-Glo; b-NAm; c-SAm; d-Afr; e-Oce; f-Eur; g-NAs; h-ESE; i-SSW).

geographic regions can be classified into three types based on features: 1) Glo, NAm, Eur and NAs, where tundra belts and ice sheet belts with an ephemeral growing season are widely distributed, have similar features, that is, 'non-vegetation coverage' proportions have significant intra-annual variations that show a ' $U$ '-shaped curve with a valley from June to September. Additionally, pixel ratios in the first quadrant that show a ' $\cap$ '-shaped curve are significantly increased in the growing season, and pixel ratios in the second quadrant show a 'reversed $\mathrm{M}^{\mathrm{\prime}}$-shaped curve with two extremely low values in April and October. Moreover, pixel ratios in the third and fourth quadrants show a 'stable'-shaped curve with intra-annual variations. 2) SAm, Oce and ESE, where the main vegetation types are tropical rainforest and tropical grassland, are located in low-middle latitudes near the Equator, and these regions have broadly similar features, that is, 'nonvegetation coverage' proportions are relatively low and have nearly no variations over 12 months. Additionally, pixel ratios in the first quadrant demonstrate an ' $M$ '-shaped curve with two peaks in April and October, and pixel ratios in the second and third

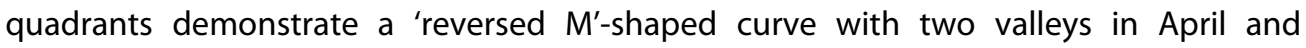
October. Moreover, pixel ratios in the fourth quadrant demonstrate a ' $\cap$ '-shaped curve with a peak in April. 3) Afr and SSW, with main vegetation types of tropical rainforest 
and tropical grassland, have obvious dry and wet seasons, and the features in these regions are different from those in other regions, that is, 'non-vegetation coverage' proportions and pixel ratios in the second and third quadrants reveal a ' $\cap$ '-shaped curve with a peak from June to October, while pixel ratios in the first and fourth quadrants demonstrate a ' $U$ '-shaped curve with a valley from June to October.

Figure 7 further shows that, in addition to 'non-vegetation coverage' areas, most pixels fall into the first and second quadrants across the whole study area and eight subregions over 12 months, and these pixels have a significant positive persistence; however, the quantitative relations of the four quadrants have obvious differences in different geographic regions in each month, which indicates that change features of vegetation coverage have prominent spatial differences. Specifically, 1) in Glo, SAm, Eur and SSW, the leading vegetation coverage change characteristic is 'increasing (persistent and anti-persistent)', which is the most notable in April and October, and 'increasing trend in the past and in the future' is the most widely distributed character. 2) In NAm and NAs, the overall vegetation coverage trend is decreasing from December to May, and areas with 'decreasing trend in the past and in the future' spread most widely; additionally, there is an overall increasing trend from June to November, which is the most significant in September, and 'increasing trend in the past and future' areas are most widespread; the reason for these results is that North America and North Asia are mostly covered by frigid zone, subfrigid zone and temperate zone vegetation. 3) In Oce and ESE, areas with increasing trends of vegetation coverage account for the largest area from January to November, a trend that is the most prominent in April, and persistent increases comprise the predominant trend; furthermore, areas with decreasing trends are the most widespread type of area in December, and persistent decreases comprise the predominant trend. 4) In Afr, the dominant vegetation coverage change characteristic is 'decreasing (persistent and anti-persistent)' from July to October, and 'decreasing trend in the past and future' is distributed most widely; moreover, the dominant characteristic is 'increasing (persistent and anti-persistent)' from November to June, and 'increasing trend in the past and future' is distributed most widely; the reason for these results is that Africa has obvious dry and wet seasons.

\subsection{Changes in vegetation coverage on a seasonal scale}

Based on the coupling characteristics of $\beta$ and $\mathrm{H}-0.5$ at the monthly scale, the seasonal characteristics of vegetation coverage change in the global coastal zone can be summarized at the pixel scale as follows: In the Northern Hemisphere, spring is from March to May and summer is from June to August; furthermore, autumn is from September to November and winter is from December to February. For the 3 months of each season, the evolution characteristics of vegetation coverage are calculated the pixel scale, that is, for each pixel, if 2 or 3 of the 3 months belong to the same character, the type of change of the pixel in the given season will be defined as this evolution character, and if there is a different character for each of the 3 months, the pixel will be defined as unstable for the given season. Subsequently, the abovementioned classified vegetation evolution information in the four seasons at the pixel scale were synthesized to obtain the map of seasonal NDVI successions (Figure 8) and the statistical characteristics of these successions (Table 4). The main findings are as follows: 


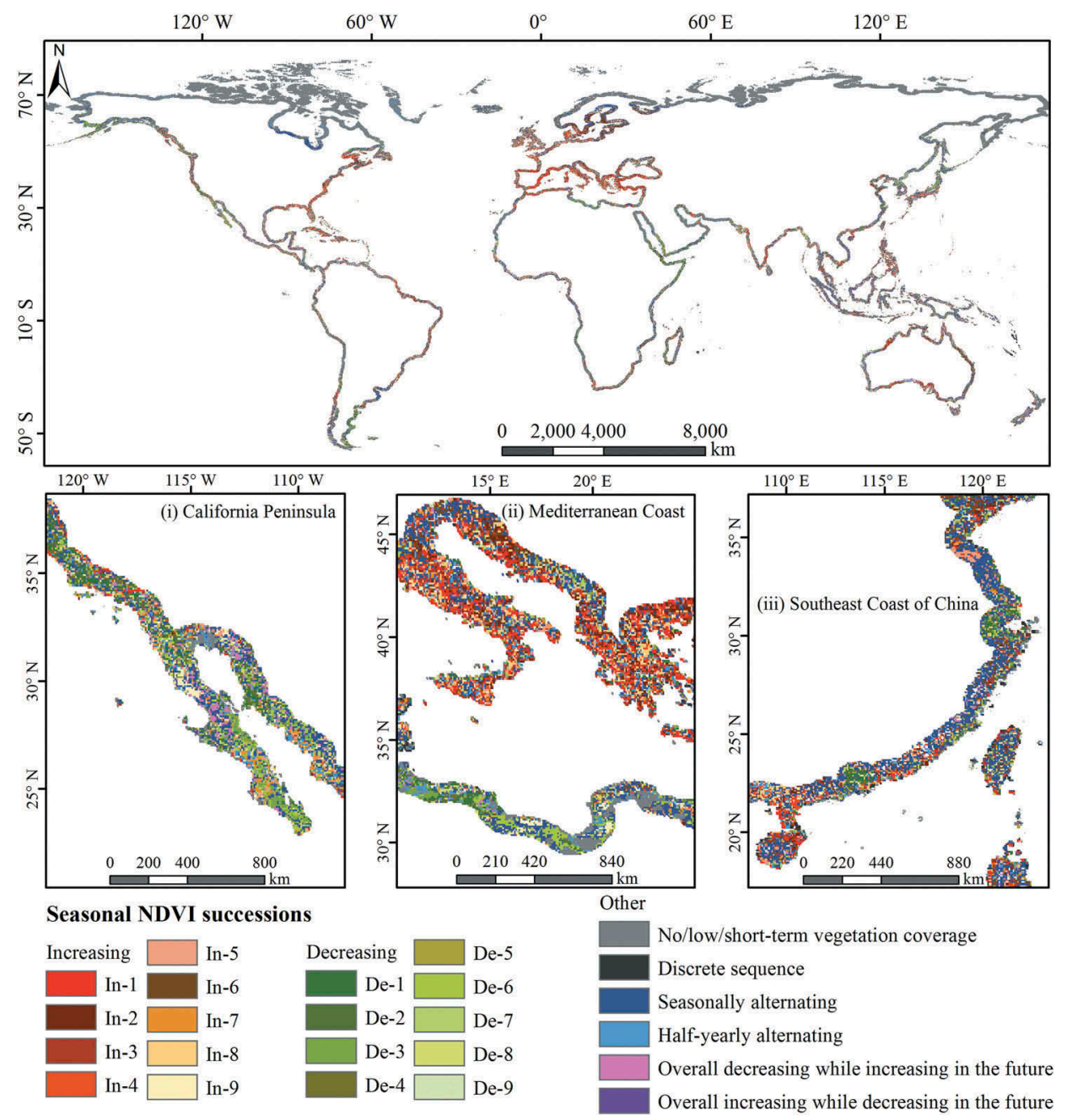

Figure 8. Map of seasonal NDVI successions in the global coastal zone.

(In-1: Increasing and increasing in the future in all four seasons; In-2: increasing and increasing in the future in spring, summer and autumn; In-3: increasing and increasing in the future in winter, spring and summer; In-4: increasing and increasing in the future in summer, autumn and winter; In-5: increasing and increasing in the future in autumn, winter and spring; In-6: increasing and increasing in the future in spring and summer; In-7: increasing and increasing in the future in winter and spring; In-8: increasing and increasing in the future in summer and autumn; In-9: increasing and increasing in the future in autumn and winter; De-1: decreasing and decreasing in the future in all four seasons; De-2: decreasing and decreasing in the future in spring, summer and autumn; De-3: decreasing and decreasing in the future in winter, spring and summer; De-4: decreasing and decreasing in the future in summer, autumn and winter; De-5: decreasing and decreasing in the future in autumn, winter and spring; De-6: decreasing and decreasing in the future in spring and summer; De-7: decreasing and decreasing in the future in winter and spring; De-8: decreasing and decreasing in the future in summer and autumn; De-9: decreasing and decreasing in the future in autumn and winter.)

Areas of 'no/low/short-term vegetation coverage' account for $24.95 \%$ of the whole area and mainly include high-latitude $\left(>60^{\circ} \mathrm{N}\right)$ tundra belts with an ephemeral growing season in the Northern Hemisphere and low-middle latitude desert belts where there is nearly no vegetation coverage; the proportions of these areas in NAm, NAs and SSW are $44.66 \%, 79.81 \%$ and $25.13 \%$, respectively. 
Table 4. Statistical characteristics of seasonal NDVI successions.

\begin{tabular}{|c|c|c|c|c|c|c|c|c|c|}
\hline \multirow[b]{2}{*}{ Seasonal NDVI succession } & \multicolumn{9}{|c|}{ Area proportion for geographic region (\%) } \\
\hline & Glo & NAm & SAm & Afr & Oce & Eur & NAs & ESE & SSW \\
\hline No/low/short-term vegetation coverage & 24.95 & 44.66 & 8.95 & 15.17 & 3.48 & 17.70 & 79.81 & 3.68 & 25.13 \\
\hline Discrete sequence & 1.64 & 0.10 & 0.61 & 5.39 & 3.20 & 0.45 & 0.07 & 2.41 & 1.75 \\
\hline Seasonally alternating & 25.54 & 18.83 & 32.70 & 26.53 & 32.07 & 25.33 & 9.00 & 37.86 & 19.23 \\
\hline Half-yearly alternating & 4.84 & 4.92 & 5.32 & 6.13 & 5.94 & 3.44 & 1.78 & 4.55 & 6.73 \\
\hline Overall increasing and increasing in the future & 24.72 & 18.13 & 27.39 & 20.00 & 29.60 & 42.21 & 2.91 & 28.49 & 30.08 \\
\hline Overall decreasing and decreasing in the future & 12.42 & 10.35 & 16.30 & 18.96 & 14.15 & 6.95 & 5.00 & 14.57 & 13.54 \\
\hline Overall decreasing while increasing in the future & 2.13 & 1.83 & 2.39 & 2.44 & 4.79 & 0.40 & 0.92 & 3.16 & 0.85 \\
\hline Overall increasing while decreasing in the future & 3.76 & 1.18 & 6.34 & 5.38 & 6.77 & 3.52 & 0.51 & 5.28 & 2.69 \\
\hline
\end{tabular}

A total of $25.54 \%$ of the whole area belongs to 'seasonally alternating', which is the most widespread type of area and is mainly distributed from $60^{\circ} \mathrm{N}$ to $50^{\circ} \mathrm{S}$. In addition to 'no/low/short-term vegetation coverage', other seasonal successions are dispersed within the leading area; the vegetation types in these regions are mostly temperate mixed forest, temperate deciduous broad-leaved forest, subtropical evergreen hardwood forest, subtropical evergreen broad-leaved forest, tropical grassland and tropical rainforest.

A total of $24.72 \%$ of the whole area belongs to the 'overall increasing and increasing in the future' category, which is spread widely in the global coastal zone. Furthermore, the percentages of 'overall increasing and increasing in the future' areas in NAm, Afr and NAs, which are $18.13 \%, 20.00 \%$ and $2.91 \%$, respectively, are lower than those in Glo, and the percentages of 'overall increasing and increasing in the future' areas in SAm, Oce, Eur, ESE and SSW, which are 27.39\%, 29.60\%, 42.21\%, 28.49\% and 30.08\%, respectively, are higher than those in Glo. Accordingly, 'overall decreasing and decreasing in the future' areas, which are also widespread in the global coastal zone, amount to $12.42 \%$ of the total area, and this seasonal succession shows 'locally concentrated' spatial patterns, that is, the distributions aggregating in 'circum urban agglomeration' and 'nearby desert belt' areas are relatively obvious, such as the city circle of the Yangtze River Delta in China, metropolitan area of the west coasts of America and Mexico, and low-middle latitude desert belts; thereinto, the proportions in NAm, Eur and NAs, which are $10.35 \%$, $6.95 \%$ and $5.00 \%$, respectively, are lower than those in Glo, and the proportions in SAm, Afr, Oce, ESE and SSW, which are 16.30\%, 18.96\%, 14.15\%, 14.57\% and $13.54 \%$, respectively, are higher than those in Glo.

The abovementioned two seasonal NDVI successions can be divided into 18 specific subclasses. Specifically, areas of 'increasing and increasing in the future in all four seasons' in Glo, NAm, SAm, Eur, ESE and SSW are the most widespread subclass, and the vegetation types in these regions are mainly temperate mixed forest, temperate deciduous broad-leaved forest, subtropical evergreen hardwood forest and tropical rainforest; 'increasing and increasing in the future in winter and spring' is the most widely distributed subclass in Afr, where the vegetation type is mostly tropical rainforest, because the growing season in Africa is in winter and spring; 'increasing and increasing in the future in spring and summer' is the most widely distributed succession in Oce, where the vegetation type is mainly tropical rainforest; areas of 'decreasing and decreasing in the future in winter and spring' are the most widespread subclasses in NAs, where the vegetation types are mainly subfrigid coniferous forest and tundra. 


\section{Conclusion and discussion}

\subsection{Summary and conclusions}

The spatial-temporal changes of vegetation coverage in the global coastal zone from 1982 to 2014 were revealed using the GIMMS NDVI3g data. The specific aims were to reflect the spatial patterns of vegetation coverage by the average annual NDVI values; to display the intra-annual and inter-annual variations of vegetation coverage by the regional average NDVI values; to analyse the change trends of vegetation coverage via the Mann-Kendall trend test; to study the future evolutions of vegetation coverage using the Hurst index; and to discuss the seasonal changes of vegetation coverage based on the seasonal succession map. The main conclusions are as follows:

(1) The average annual NDVI spatial patterns indicate that areas with perennial nonvegetation coverage and low vegetation coverage are mainly in the desert belts, and tundra belts on the northern coasts of North America and Eurasia mostly have moderate vegetation coverage and high vegetation coverage. Moreover, temperate mixed forest, temperate deciduous broad-leaved forest, subtropical evergreen hardwood forest, subtropical evergreen broad-leaved forest, tropical grassland and tropical rainforest areas are centrally distributed in areas with dense vegetation coverage. Apparently, tundra belts have a relatively high annual NDVI because annual NDVI mainly shows vegetation coverage information in the peak time of the whole growth season.

(2) Intra-annual and inter-annual variations in vegetation coverage show that Glo, NAm, Eur, NAs and ESE have significant alternating features in both the growing and non-growing seasons, which show a ' $\cap$ '-shaped curve with an obvious peak from June to September, and Afr shows a 'U'-shaped curve with a valley from July to October. Moreover, SAm, Oce and SSW show a 'stable'-shaped curve that has no obvious seasonal differences. The reason for intra-annual variation differences is that the growing and non-growing seasons in these regions have significant differences. NDVI values in different geographic regions from 1982 to 2014 all fluctuate but show a generally slow increasing trend with highly consistent fluctuations.

(3) For change trends of vegetation coverage at annual and monthly scales, areas with increasing trends are the most widespread in the global coastal zone, while there are relatively few areas with decreasing trends, which are mostly 'insignificantly decreasing'. Overall, increasing trend regions are mostly spread in highlatitude tundra belts, middle-latitude temperate mixed forest and temperate deciduous broad-leaved forest belts, and low-latitude tropical grassland and tropical rainforest belts, while decreasing trend regions show the 'locally concentrated' spatial patterns, mainly aggregating in coastal urban agglomerations and desert belt peripheries. Notably, the increasing trend in vegetation coverage is extremely significant in the high-latitude tundra belt because annual NDVI obtained from MVC method reflects coverage information in the high-growth season. 
(4) The coupling characteristics of $\beta$ and $H-0.5$ at the pixel scale reveal that Glo, SAm, Eur and SSW, where the increasing trend in vegetation coverage has a relatively strong positive persistence that is the most notable in April and October, have overall positive ecological conditions. A 'decreasing (persistent)' trend in vegetation coverage in NAm and NAs is most widespread from December to May, and areas with a 'decreasing (persistent)' trend in Oce and ESE are predominant in December; furthermore, the dominant change type in Afr is 'decreasing (persistent)' from July to October; therefore, in these regions, vegetation degradation is relatively serious, and projections for future evolutions are not optimistic.

(5) Based on seasonal succession map over the global coastal zone, 'overall increasing and increasing in the future' areas are widespread; accordingly, 'overall decreasing and decreasing in the future' areas, which are also widespread, show the 'locally concentrated' spatial patterns, and these regions are mainly aggregated in the 'circum urban agglomeration' and 'nearby desert belt' regions, that is, the overall 'decreasing (persistent)' trend in vegetation coverage is relatively significant in coastal urban agglomerations and desert belt peripheries. Furthermore, the abovementioned two seasonal NDVI successions can be divided into 18 specific subclasses, and 'increasing and increasing in the future in all four seasons' areas is the most widespread subclass.

\subsection{Discussion and outlook}

In conclusion, vegetation coverage change in the global coastal zone from 1982 to 2014 shows relatively complex spatial-temporal characteristics. Specifically, coastal vegetation coverage in the high-latitude tundra belt, which has a highly significant increasing trend in the growing season, is highly sensitive to climate change, while coastal areas mainly located in the low-middle latitude desert belt and coastal urban agglomerations strongly affected by human activity have a significant decreasing trend in vegetation coverage. We found that the results obtained in this paper were highly consistent with the results of existing studies (Faour, Mhawej, and Nasrallah 2018; Guo et al. 2018), which reflected the effectiveness, reliability and disseminability of the results obtained in this paper. Additionally, the results obtained in this paper were distinctive, because the study of the characteristics of multi-temporal scale variation in vegetation coverage in the global coastal zone laid a solid foundation for coastal zone management.

Furthermore, the dynamic mechanisms of vegetation coverage change in the global coastal zone have been partially demonstrated; vegetation coverage change is not only affected by climate change but is also influenced by human activities. In the sparsely populated high-latitude tundra and low-middle latitude desert belts, the vegetation growth status is greatly affected by natural factors. Synthesis with existing study results (Mohammat et al. 2013; Kong et al. 2017) found that precipitation and temperature were the main influencing factors of vegetation coverage in these areas. But, in the densely populated coastal urban agglomerations, the vegetation growth status is not only influenced by natural factors but is also restricted by economics, technology, society and other human factors. Specifically, the human factors driving the evolution of vegetation coverage in these areas are extremely obvious; urbanization is one of the main causes of vegetation degradation (Wu, Liang, and Li 2019), whereas agricultural 
activities are the main human factors that promote vegetation improvement and aggravate seasonal or spatial differences in vegetation coverage.

Overall, this paper suggests that vegetation conservation should serve as an important target of coastal ecosystem management and integrated coastal zone management; accordingly, climate change adaptation and human activity regulation should be prioritized in coastal vegetation conservation. This paper has unsolved problems that are well worth addressing in further research. For example, the GIMMS NDVI3g dataset with a spatial resolution of $0.083^{\circ} \times 0.083^{\circ}$ has a large-scale effect; thus, for mixed pixels containing vegetation and non-vegetation regions, the NDVI values in low spatial resolution images are lower than those in high spatial resolution datasets. In addition, the NDVI values have a severe supersaturation effect, because the NDVI values in dense vegetation coverage regions have high saturation and low sensitivity. Finally, the detailed mechanisms of vegetation coverage change are difficult to control and understand. The findings in this paper will provide support for further studies on the abovementioned problems.

\section{Acknowledgements}

The authors are grateful to Zhenguo Niu, Chunhui Li, Xiaoli Wang, and Dong Li, who had assisted or advised them during various stages of this work.

\section{Disclosure statement}

No potential conflict of interest was reported by the authors.

\section{Funding}

This work was supported by the Strategic Priority Research Program of the Chinese Academy of Sciences (No. XDA19060205) and the National Natural Science Foundation of China (No. 31461143032).

\section{References}

Chen, B. Z., G. Xu, N. C. Coops, P. Ciais, J. L. Innes, G. Y. Wang, R. B. Myneni, et al. 2014. “Changes in Vegetation Photosynthetic Activity Trends across the Asia-Pacific Region over the Last Three Decades." Remote Sensing of Environment 144: 28-41. doi:10.1016/j.rse.2013.12.018.

De Keersmaecker, W., S. Lhermitte, M. J. Hill, L. Tits, P. Coppin, and B. Somers. 2017. "Assessment of Regional Vegetation Response to Climate Anomalies: A Case Study for Australia Using GIMMS NDVI Time Series between 1982 and 2006." Remote Sensing 9 (1): 34. doi:10.3390/rs9010034.

de la Barrera, F., and C. Henríquez. 2017. "Vegetation Cover Change in Growing Urban Agglomerations in Chile." Ecological Indicators 81: 265-273. doi:10.1016/j.ecolind.2017.05.067.

Dobbs, C., C. Nitschke, and D. Kendal. 2017. "Assessing the Drivers Shaping Global Patterns of Urban Vegetation Landscape Structure." Science of the Total Environment 592: 171-177. doi:10.1016/j.scitotenv.2017.03.058.

Du, J. Q., J. M. Shu, J. Q. Yin, X. J. Yuan, A. Jiaerheng, S. S. Xiong, P. He, and W. L. Liu. 2015. “Analysis on Spatio-temporal Trends and Drivers in Vegetation Growth during Recent Decades in Xinjiang, China." International Journal of Applied Earth Observation and Geoinformation 38: 216-228. doi:10.1016/j.jag.2015.01.006. 
Du, J. Q., J. M. Shu, C. X. Zhao, A. Jiaerheng, L. X. Wang, B. Xiang, G. L. Fang, W. L. Liu, and P. He. 2016. "Comparison of GIMMS NDVI3g and GIMMS NDVIg for Monitoring Vegetation Activity and Its Responses to Climate Changes in Xinjiang during 1982-2006." Acta Ecologica Sinica 36 (21): 6738-6749. in Chinese.

Fan, X. W., and Y. B. Liu. 2016. "A Global Study of NDVI Difference among Moderate-resolution Satellite Sensors." ISPRS Journal of Photogrammetry and Remote Sensing 121: 177-191. doi:10.1016/j.isprsjprs.2016.09.008.

Faour, G., M. Mhawej, and A. Nasrallah. 2018. "Global Trends Analysis of the Main Vegetation Types Throughout the past Four Decades." Applied Geography 97: 184-195. doi:10.1016/j. apgeog.2018.05.020.

Feng, H. H., B. Zou, and J. H. Luo. 2017. "Coverage-dependent Amplifiers of Vegetation Change on Global Water Cycle Dynamics." Journal of Hydrology 550: 220-229. doi:10.1016/j. jhydrol.2017.04.056.

Guo, M., J. Li, H. S. He, J. W. Xu, and Y. H. Jin. 2018. “Detecting Global Vegetation Changes Using Mann-Kendal (MK) Trend Test for 1982-2015 Time Period." Chinese Geographical Science 28 (6): 907-919. doi:10.1007/s11769-018-1002-2.

Halkos, G., and S. Matsiori. 2018. "Environmental Attitudes and Preferences for Coastal Zone Improvements." Economic Analysis and Policy 58: 153-166. doi:10.1016/j.eap.2017.10.002.

Hamed, K. H. 2009. "Exact Distribution of the Mann-Kendall Trend Test Statistic for Persistent Data." Journal of Hydrology 365: 86-94. doi:10.1016/j.jhydrol.2008.11.024.

Holben, B. N. 1986. "Characteristics of Maximum-value Composite Images from Temporal AVHRR Data." International Journal of Remote Sensing 7 (11): 1417-1434. doi:10.1080/01431168608948945.

Hou, X. Y., T. Wu, L. J. Yu, and S. Qian. 2012. "Characteristics of Multi-temporal Scale Variation of Vegetation Coverage in the Circum Bohai Bay Region, 1999-2009." Acta Ecologica Sinica 32: 297-304. doi:10.1016/j.chnaes.2012.08.001.

Ju, J. C., and J. G. Masek. 2016. "The Vegetation Greenness Trend in Canada and US Alaska from 1984-2012 Landsat Data." Remote Sensing of Environment 176: 1-16. doi:10.1016/j.rse.2016.01.001.

Kim, D., M. Chin, L. A. Remer, T. Diehl, H. S. Bian, H. B. Yu, M. E. Brown, and W. R. Stockwell. 2017. "Role of Surface Wind and Vegetation Cover in Multi-decadal Variations of Dust Emission in the Sahara and Sahel." Atmospheric Environment 148: 282-296. doi:10.1016/j. atmosenv.2016.10.051.

Kong, D. D., Q. Zhang, V. P. Singh, and P. J. Shi. 2017. "Seasonal Vegetation Response to Climate Change in the Northern Hemisphere (1982-2013)." Global and Planetary Change 148: 1-8. doi:10.1016/j.gloplacha.2016.10.020.

Lamchin, M., W. K. Lee, S. W. Jeon, S. W. Wang, C. H. Lim, C. Song, and M. Sung. 2017. "Longterm Trend and Correlation between Vegetation Greenness and Climate Variables in Asia Based on Satellite Data." Science of the Total Environment 618: 1089-1095. doi:10.1016/j. scitotenv.2017.09.145.

Lanfredi, M., T. Simoniello, and M. Macchiato. 2004. "Temporal Persistence in Vegetation Cover Changes Observed from Satellite: Development of an Estimation Procedure in the Test Site of the Mediterranean Italy." Remote Sensing of Environment 93: 565-576. doi:10.1016/j. rse.2004.08.012.

Latifovic, R., D. Pouliot, and C. Dillabaugh. 2012. "Identification and Correction of Systematic Error in NOAA AVHRR Long-term Satellite Data Record." Remote Sensing of Environment 127: 84-97. doi:10.1016/j.rse.2012.08.032.

Liu, Y., C. Z. Li, Z. H. Liu, and X. Y. Deng. 2016. "Assessment of Spatio-temporal Variations in Vegetation Cover in Xinjiang from 1982 to 2013 Based on GIMMS-NDVI." Acta Ecologica Sinica 36 (19): 6198-6208. in Chinese.

Masria, A., A. Negm, M. Iskander, and O. Saavedra. 2014. "Coastal Zone Issues: a Case Study (egypt)." Procedia Engineering 70: 1102-1111. doi:10.1016/j.proeng.2014.02.122.

Miao, L. J., Q. Liu, R. Fraser, B. He, and X. F. Cui. 2015. "Shifts in Vegetation Growth in Response to Multiple Factors on the Mongolian Plateau from 1982 to 2011." Physics and Chemistry of the Earth 87-88: 50-59. doi:10.1016/j.pce.2015.07.010. 
Mohammat, A., X. H. Wang, X. T. Xu, L. Q. Peng, Y. Yang, X. P. Zhang, R. B. Myneni, and S. L. Piao. 2013. "Drought and Spring Cooling Induced Recent Decrease in Vegetation Growth in Inner Asia." Agricultural and Forest Meteorology 178-179: 21-30. doi:10.1016/j.agrformet.2012.09.014.

Pang, G. J., X. J. Wang, and M. X. Yang. 2017. "Using the NDVI to Identify Variations In, and Responses Of, Vegetation to Climate Change on the Tibetan Plateau from 1982 to 2012." Quaternary International 444: 87-96. doi:10.1016/j.quaint.2016.08.038.

Peng, J., Z. H. Liu, Y. H. Liu, J. S. Wu, and Y. N. Han. 2012. "Trend Analysis of Vegetation Dynamics in Qinghai-Tibet Plateau Using Hurst Exponent." Ecological Indicators 14: 28-39. doi:10.1016/j. ecolind.2011.08.011.

Pereira, P., A. Cerda, A. Jordan, V. Bolutiene, M. Pranskevicius, X. Ubeda, and J. Mataix-Solera. 2013. "Spatio-temporal Vegetation Recuperation after a Grassland Fire in Lithuania." Procedia Environmental Sciences 19: 856-864. doi:10.1016/j.proenv.2013.06.095.

Pinzon, J. E., and C. J. Tucker. 2014. "A Non-Stationary 1981-2012 AVHRR NDVI3g Time Series." Remote Sensing 6: 6929-6960. doi:10.3390/rs6086929.

Rêgo, J. C. L., A. Soares-Gomes, and F. S. Da Silva. 2018. "Loss of Vegetation Cover in a Tropical Island of the Amazon Coastal Zone (Maranhão Island, Brazil)." Land Use Policy 71: 593-601. doi:10.1016/j.landusepol.2017.10.055.

Sánchez Granero, M. A., J. E. Trinidad Segovia, and J. García Pérez. 2008. "Some Comments on Hurst Exponent and the Long Memory Processes on Capital Markets." Physica A 387: 5543-5551. doi:10.1016/j.physa.2008.05.053.

Shafapour Tehrany, M. S., L. Kumar, and M. J. Drielsma. 2017. "Review of Native Vegetation Condition Assessment Concepts, Methods and Future Trends." Journal for Nature Conservation 40: 12-23. doi:10.1016/j.jnc.2017.08.004.

Shi, H., and A. Singh. 2003. "Status and Interconnections of Selected Environmental Issues in the Global Coastal Zones." AMBIO: A Journal of the Human Environment 32 (2): 145-152. in Chinese. doi:10.1579/0044-7447-32.2.145.

Tian, Y. C., X. Y. Bai, S. J. Wang, L. Y. Qin, and Y. Li. 2017. "Spatial-temporal Changes of Vegetation Cover in Guizhou Province, Southern China." Chinese Geographical Science 27 (1): 25-38. doi:10.1007/s11769-017-0844-3.

Vicente-Serrano, S. M., J. Julio Camarero, J. M. Olano, N. Martín-Hernández, M. Peña-Gallardo, M. Tomás-Burguera, A. Gazol, C. Azorin-Molina, U. Bhuyan, and A. El Kenawy. 2016. “Diverse Relationships between Forest Growth and the Normalized Difference Vegetation Index at a Global Scale." Remote Sensing of Environment 187: 14-29. doi:10.1016/j.rse.2016.10.001.

Vrieling, A., M. Meroni, A. Shee, G. Mude, J. Woodard, C. A. J. M. (kees) de Bie, and F. Rembold. 2014. "Historical Extension of Operational NDVI Products for Livestock Insurance in Kenya." International Journal of Applied Earth Observation and Geoinformation 28: 238-251. doi:10.1016/j. jag.2013.12.010.

Wang, H., H. X. Yang, and L. Zhang. 2018. "Character of Vegetation Coverage Change along Coastal Areas of Maritime Silk Road." Remote Sensing Technology and Application 33 (4): 703-712. in Chinese.

Wu, S. Y., Z. Liang, and S. C. Li. 2019. "Relationships between Urban Development Level and Urban Vegetation States: A Global Perspective." Urban Forestry \& Urban Greening 38: 215-222. doi:10.1016/j.ufug.2018.12.010.

Xu, H. J., X. P. Wang, and T. B. Yang. 2017. "Trend Shifts in Satellite-derived Vegetation Growth in Central Eurasia, 1982-2013." Science of the Total Environment 579: 1658-1674. doi:10.1016/j. scitotenv.2016.11.182.

Yang, X. M., S. Z. Liu, T. B. Yang, X. Y. Xu, C. Z. Kang, J. N. Tang, H. D. Wei, M. G. Ghebrezgabher, and Z. Q. Li. 2016. "Spatial-temporal Dynamics of Desert Vegetation and Its Responses to Climatic Variations over the Last Three Decades: a Case Study of Hexi Region in Northwest China." Journal of Arid Land 8 (4): 556-568. doi:10.1007/s40333-016-0046-3.

Yue, S., P. Pilon, and G. Cavadias. 2002. "Power of the Mann-Kendall and Spearman's Rho Tests for Detecting Monotonic Trends in Hydrological Series." Journal of Hydrology 259: 254-271. doi:10.1016/S0022-1694(01)00594-7. 
Zhang, Y., Z. C. Zhu, Z. Liu, Z. Z. Zeng, P. Ciais, M. T. Huang, Y. W. Liu, and S. L. Piao. 2016. "Seasonal and Interannual Changes in Vegetation Activity of Tropicalforests in Southeast Asia." Agricultural and Forest Meteorology 224: 1-10. doi:10.1016/j.agrformet.2016.04.009.

Zhao, L., A. Dai, and B. Dong. 2018. "Changes in Global Vegetation Activity and Its Driving Factors during 1982-2013." Agricultural and Forest Meteorology 249: 198-209. doi:10.1016/j. agrformet.2017.11.013. 